\title{
Use of coal beneficiation tailings as solid sorbents in the treatment of nitrate-contaminated real wastewater
}

\author{
Keila Guerra Pacheco Nunes ${ }^{1}\left[\right.$ ] Júlia Carolina Illi $^{1} \cdot$ Ivone Vanessa Jurado Dávila ${ }^{1}$ Liliana Amaral Feris ${ }^{1}$
}

Received: 11 October 2019 / Accepted: 26 February 2020 / Published online: 14 March 2020

(c) The Author(s) 2020

\begin{abstract}
This work evaluates the application efficiency of coal tailings beneficiation as a solid sorbent in the treatment of real wastewater contaminated with nitrate. The solid was characterized by XDR, SEM, FTIR and TGA. Adsorption experiments were performed in batch evaluating the effects of $\mathrm{pH}$, solids concentration and contact time parameters. The kinetics of nitrate adsorption was evaluated using pseudo-first-order and pseudo-second-order models. Equilibrium isotherms for this system were analyzed at three different temperatures $(298,308$ and $318 \mathrm{~K}$ ) by Langmuir, Freundlich and Sips models. The best results from the adsorption experiments were $\mathrm{pH} 6$, contact time of $60 \mathrm{~min}$ and $1 \mathrm{~g} 100 \mathrm{~mL}^{-1}$ of solid. The thermodynamics model that best described the behavior of the process was Sips. By applying these conditions to real wastewater, a nitrate removal of $93 \%$ was achieved. This result shows that adsorption using coal beneficiation tailings is technically possible.
\end{abstract}

Keywords Nitrate $\cdot$ Coal tailings $\cdot$ Sorption $\cdot$ Real wastewater

\section{Introduction}

The contamination of surface water, groundwater and soil is a worldwide problem. There is a great concern with available natural resources, and the reuse of water is an implemented practice in industrial and agricultural sectors. However, surface water, groundwater and industrial effluents have organic and inorganic chemical compounds in their composition that cause various harmful effects to living beings and the environment (Davis and Cornwell 2012).

Nitrate is among the pollutants identified as a critical water and effluent contaminant. This compound has high stability and solubility in water and low potential of precipitation. It is important to observe that nitrate is essential to ecosystems, but at high quantities, it becomes extremely harmful for both human health and the environment. In children under the age of three, for example, high concentrations of nitrate may cause methemoglobinemia (blue baby syndrome), which happens when the microorganisms of the stomach convert nitrate ions into nitrite ions, which enter

Keila Guerra Pacheco Nunes

keila@enq.ufrgs.br

1 Department of Chemical Engineering, Federal University of Rio Grande DO Sul (UFRGS), Ramiro Barcelos Street, 2777, 90035-007 Porto Alegre, RS, Brazil the bloodstream and convert the hemoglobin into methemoglobin, thus reducing the transport of oxygen to cells (Davis and Cornwell 2012; Fan et al. 1987). In adults, the kidneys rapidly excrete the nitrate; therefore, it is hard to convert it into nitrite. However, studies warn of an increase in certain types of cancer associated with high concentrations of nitrate in drinking water. Nitrate, which might be converted into nitrite, can react with secondary amines to form nitrosamides and nitrosamines, which are compounds with carcinogenic effects (Alaburda and Nishihara 1998; Pennington 1998). In the environment, the excess of nitrogen may result in a reduction in dissolved oxygen in water bodies and cause eutrophication, which promotes the growth of algae, such as cyanobacteria, that release toxins harmful to human health (Le Moal et al. 2019; Drzeżdżon et al. 2018).

Researchers have listed several nitrate sources. The main ones are the disposal of untreated domestic sewage, uncontrolled industrial waste and excessive use of agricultural fertilizers (Davis and Cornwell 2012; Zhao et al. 2010; Cecconet et al. 2018). Due to the above-mentioned characteristics, the removal of this ion from contaminated water by conventional processes of filtration and decantation is still inefficient (Al-Ghouti et al. 2019).

Many technologies have been used in water treatment, including ion exchange (Khan et al. 2018, 2019a, b), reverse osmosis, reduction, precipitation, and membrane 
filtrations (Kolangare et al., 2018; Rungrodnimitchai and Kotatha 2019; Sheikh et al. 2019; Roudbari and Rezakazemi 2018; Erkan et al. 2018). Among various technologies for treatment, adsorption has been explored extensively and presents satisfactory results, especially using adsorbents of mineral origin and/or modified surface (Samatya et al. 2006; Xi et al. 2010; Bhatnagar and Sillanpää 2011; Zanella et al. 2015; Tyagi et al. 2018; Madhura et al. 2018; Tara and Asiri 2020). Adsorption, compared to other methods, is very attractive mainly in terms of design simplicity, easy operation and economic factors when lowcost sorbents are used.

The literature reports several studies concerning nitrate removal by adsorption (Pan et al. 2019; Viglasova et al. 2018; Kuang et al. 2018; He et al. 2020). Adsorbents, such as activated carbon, clays, hydrotalcites, zeolites, chitosan, agricultural waste, industrial waste and others, can be applied with efficiency levels over $80 \%$ (Bhatnagar and Sillanpää 2011). Chemical modification is also cited as a potential alternative to improve nitrate removal. Zanella et al. (2015) obtained around 70\% by treating activated carbon with calcium chloride. As activated carbon is negatively charged, nitrate retention by electrostatic interactions is usually very low.

Xie et al. (2017) used mineral clay waste in the process of nitrate sorption, applying tensoactive HDTMA-Br to modify the mineral's surface, thus obtaining a maximum rate of nitrate removal of about $15 \mathrm{mg} \mathrm{g}^{-1}$. The adsorbent superficial modification with cationic surfactant allows simultaneous adsorption of anions, cations and apolar organic molecules from water. Therefore, there may be hydrophobic and hydrophilic parts and positive and negative parts after modification (Churchman et al. 2006; Guan et al. 2010).

Another environmental problem is coal extraction and processing activities, which generate extremely high amounts of solid waste. The coal extracted in mines is shipped to processing plants. For each ton of ROM (run of mine) coal processed, around $60 \%$ of solid waste is generated. Such tailings are deposited in modules located near mining areas and comprise basically carbon materials and minerals with no commercial value. In the presence of water and oxygen, the tailings oxidize, causing acid mine drainage and generating risk of contamination of surface water, groundwater and soil (Munawer 2018).

It is estimated that, in 2017 , more than ten million tons of ROM coal was extracted in southern Brazil, and about $50 \%$ of this amount came from mining areas in Santa Catarina (SIECESC 2017). According to a study by Silva et al. (2018) at the coal mining company Criciúma S/A-Unidade de Mineração II-Verdinho, from the total mass of initial ore, which is benefited by jig (ore concentration process by water agitation), only $30 \%$ results in products; the remainder is discarded as solid residue. This waste is classified according to ABNT NBR 10.004 (2004) as a Class II nonhazardous solid waste-non-inert.

Considering the growing concern with environmental issues, there is a need to study applications for such solid wastes generated in coal beneficiation, as well as to minimize the impacts of waste on the environment. Thus, the present work studies the application of a coal beneficiation tailing for nitrate removal by adsorption.

\section{Materials and methods}

\section{Materials}

Coal beneficiation tailing of the coal mining company Criciúma S/A of Santa Catarina, Brazil (2.80-1.65 mm), was used as a solid sorbent. Hexadecyltrimethylammonium bromide-HDTMA-Br (Sigma-Aldrich Brazil Ltda) $60 \mathrm{mM}-$ was used for chemical surface modification of the solid. Sodium hydroxide (Synth), hydrochloric acid (Vetec) and sulfuric acid (Anidrol) $0.1 \mathrm{M}$ were used for $\mathrm{pH}$ adjustment. Solutions of sodium nitrate (Vetec), $15 \mathrm{mg} \mathrm{L}^{-1}\left(\mathrm{NO}_{3}{ }^{-}\right)$, and water from a lake located in Viamão (Rio Grande do Sul, Brazil) were used for adsorption tests.

\section{Characterization of the solid sorbent}

The analysis of superficial area was performed using an NOVA 1000e Surface Area and Pore Size Analyzer equipment with Quantachrome Instruments. The Zeta potential analysis was performed with the Zeta Plus Brookhaven Instruments Corporation ZEEtm, model 500, equipment. MEV-EDS analyses (Hitachi, TM 3000 Tabletop Microscope) were performed using an electronic microscope coupled with spectroscopy by dispersed energy. Analyses of TGA (Mettler Toledo, TG/SDTA 851e) were performed in solids. The R1 and R1M sample diffractograms were obtained from X-ray diffractometer Bruker D2 Phaser, with radiation $\mathrm{Cu}-\mathrm{k} \alpha$, angle $2 \theta$, where $\theta$ is the incidence angle measure in degrees $\left(^{\circ}\right.$ ), between 5 and $75^{\circ}$, with a 0.02 step per second. The analysis was performed before and after the adsorption. To identify a large number of chemical elements in the study sample, X-ray fluorescence was used. To perform the analysis, the Shimadzu XRF-1180 spectrophotometer was used. The surface structure of the solids was explored with Fourier-transform infrared (FTIR) spectroscopy to illustrate changes in the functional groups of the coal surface before and after adsorption.

\section{Solid chemical modification}

The coal beneficiation tailing residue, called R1 in this work, was sieved $(2.80-1.65 \mathrm{~mm})$, washed with distilled water and 
dried at $100{ }^{\circ} \mathrm{C}$ for $24 \mathrm{~h}$. Finally, the solid R1 was calcined at $973 \mathrm{~K}$ in a muffle furnace, in air atmosphere. The dry sample was stored in a desiccator.

Aiming to improve sorption capacity, the surface was chemically modified. The modification was performed by stirring in Wagner shaker $10 \mathrm{~g}$ of R1 with $200 \mathrm{~mL}$ of HDTMA-Br $60 \mathrm{M}$ solution for $24 \mathrm{~h}$ at room temperature $(293 \mathrm{~K})$. After this step, the solid was separated and dried at $373 \mathrm{~K}$ for $24 \mathrm{~h}$. Once dried, the solid was sieved to achieve a size from 0.1 to $0.2 \mathrm{~mm}$. After this treatment, the solid sorbent was called R1M.

\section{Adsorption experiments}

\section{Effect of $\mathrm{pH}$}

Experiments for evaluation of the $\mathrm{pH}$ effect were carried out in a batch system using $100 \mathrm{~mL}$ of $\mathrm{t} \mathrm{NO}_{3}{ }^{-}$solution with $0.50 \mathrm{~g}$ of solid residue. The $\mathrm{pH}$ adjustment in different values was performed using $\mathrm{HCl}$ and $\mathrm{NaOH} 0.1 \mathrm{M}$. The mixture was kept in contact for 30 min before the solid-liquid separation. Nitrate concentration was determined according to the method 4500- $\mathrm{NO}_{3}{ }^{-} \mathrm{B}$ (USEPA 1994), using the wavelength $210 \mathrm{~nm}$ (Calibration curve: $R^{2}=0.9991 ; y=0.1605 x$ ).

\section{Effect of residence time}

The study of contact time influence in the process was performed using $100 \mathrm{~mL}$ of $\mathrm{NO}_{3}{ }^{-}$solution, $0.5 \mathrm{~g}$ of solid and contact times of 5, 10, 20, 30, 40, 60, 75 and $90 \mathrm{~min}$. The $\mathrm{pH}$ was adjusted to the value which obtained the best adsorption results for nitrate removal in section "Effect of $\mathrm{pH}$ ".

\section{Solid adsorbent concentration determination}

Different concentrations of solid adsorbent were evaluated $\left(2,5,8,10,15,20 \mathrm{~g} \mathrm{~L}^{-1}\right)$. For each experiment, $100 \mathrm{~mL}$ of $\mathrm{NO}_{3}{ }^{-}$solution was stirred with the solid during the contact time determined in section "Effect of residence time" at the $\mathrm{pH}$ determined in section "Effect of $\mathrm{pH}$ ".

\section{Adsorption kinetic}

In the kinetic tests, the vials were shaken at predetermined times (5-210 $\mathrm{min}$ ). The experimental data were analyzed using the kinetic models of pseudo-first order (Eq. 1) and pseudo-second order (Eq. 2):

$q_{t}=q_{e}\left(1-e^{-k_{1} t}\right)$

$q_{t}=\frac{q_{e}^{2} k_{2} t}{1+q_{e} k_{2} t}$, where $q_{e}$ is the amount of solute adsorbed $\left(\mathrm{mg} \mathrm{g}^{-1}\right)$ at equilibrium, $q_{t}$ is the amount of solute adsorbed $\left(\mathrm{mg} \mathrm{g}^{-1}\right)$ at time, $k_{1}$ is the pseudo-first order $\left(\mathrm{min}^{-1}\right)$ and $k_{2}$ is the pseudosecond order $\left(\mathrm{g} \mathrm{mg}^{-1} \mathrm{~min}^{-1}\right)$.

\section{Adsorption isotherms and Thermodynamic}

The experiments were carried out in a batch scale using $100 \mathrm{~mL}$ of samples with different $\mathrm{NO}_{3}{ }^{-}$concentrations at three different temperatures (298, 308 and $318 \mathrm{~K})$. The conditions of $\mathrm{pH}$, contact time and solid concentration used to analyze the adsorption isotherms were those obtained in sections "Effect of pH", "Effect of residence time" and "Solid adsorbent concentration determination". The results were used to determine the thermodynamic behavior of the process (Rezakazemi and Shirazian 2019).

\section{Adsorption experiments using real wastewater}

Adsorption tests were performed with a real wastewater sample under the best conditions obtained for nitrate solutions in batch experiments. Water from a polluted lake located in Viamão (RS, Brazil) was sampled, stored in plastic bottles and kept refrigerated. The adsorption tests were performed in duplicate. The initial and final analyses were performed by ion chromatography on a Dionex ICS-500. Bromide, chloride, fluoride, nitrate, nitrite and sulfate ions were determined.

\section{Results and discussion}

\section{Characterization of adsorbent solid}

Table 1 shows data of the adsorbent solid characterization used in this study.

According to Table 1, the superficial area of R1M showed a small increase when compared to R1. This was expected, since there was a thermal activation of the solid waste. Ruthven (1984) explained that when the thermal activation is performed at high temperatures (973-1273 K), there is the removal of carbonization products, which makes the pores on the surface of the solid unobstructed, thus increasing

Table 1 Characterization from the residue R1

\begin{tabular}{lllll}
\hline & $\begin{array}{l}\text { Specific mass } \\
\left(\mathrm{kg} \mathrm{m}^{-3}\right)\end{array}$ & $\begin{array}{l}\text { Superficial area } \\
\left(\mathrm{m}^{2} \mathrm{~kg}^{-1}\right)\end{array}$ & $\begin{array}{l}\text { Pore volume } \\
\left(\mathrm{m}^{3} \mathrm{~kg}^{-1}\right)\end{array}$ & $\begin{array}{l}\text { Pore } \\
\text { diameter } \\
(\mathrm{nm})\end{array}$ \\
\hline $\mathrm{R} 1$ & 2.111 & 4.425 & $1.310^{-5}$ & 3.080 \\
$\mathrm{R} 1 \mathrm{M}$ & 2.112 & 4.900 & $9.010^{-6}$ & 3.064 \\
\hline
\end{tabular}

R1: coal beneficiation tailing, R1M: coal beneficiation tailing calcinated and chemically modified 
surface area and porosity. The explanation of Ruthven (1984) confirms the data obtained in this study, since calcination was the result of an increase in available pores per unit of mass. A larger increase in the surface area was expected, but was not observed. It is possibly related to the adsorption of molecules of the surfactant HDTMA-Br on the external surface of the solid, since the reagent was used to modify the superficial charge of the adsorbent solid and may

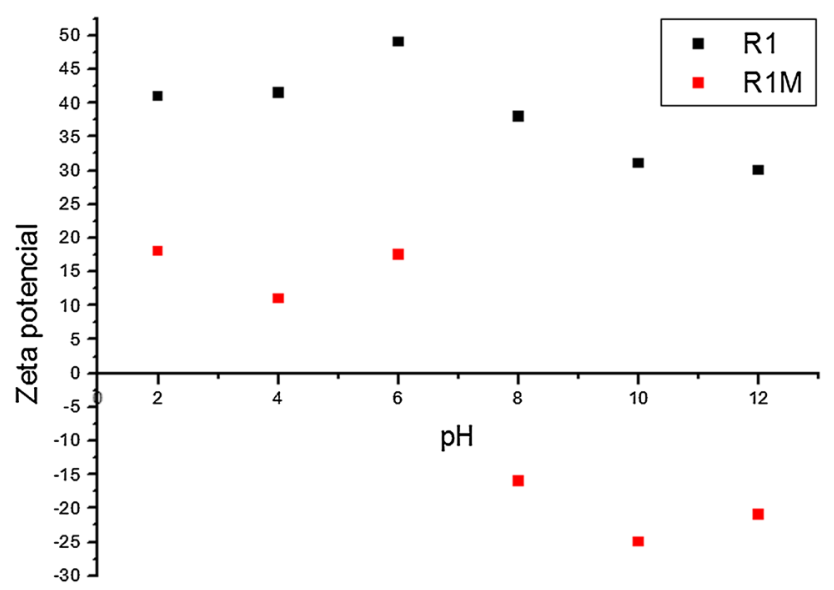

Fig. 1 Zeta potential measurements of coal beneficiation tailing R1 and coal beneficiation tailing calcinated and chemically modified RIM have blocked micropores. Xi et al. (2010) performed sorption tests with solids of clay minerals (bentonite, kaolinite and halloysite) modified with HDTMA-Br and, in tests of superficial area, found results similar as those of this study, where the area decreased after chemical modification. Tohdee et al. (2018) used the reagent HDTMA-Br to modify the solid surface for phenol removal using bentonite as sorbent. The results showed that surface modification caused a reduction in the values of the superficial area, a fact that the authors are related to the aggregation of quaternary ammonium salts of tenside, which possibly blocked the pores, thus preventing the input of nitrogen gas during the BET analysis.

Figure 1 shows a comparison between the zeta potential from the residue $\mathrm{R} 1$ and the $\mathrm{R} 1 \mathrm{M}$.

According to Fig. 1, the modified residue (R1M) is the solid that presented the best characteristics for nitrate adsorption, i.e., there are more positive charges on the surface, consequently a greater tendency to electrostatically attract ions with a negative charge, such as nitrate. The fact that zeta potential was totally positive in the sample R1M shows that the modification performed in calcined waste was effective.

Figure 2 presents SEM images and the elemental composition of each solid (R1 and R1M, respectively).

According to the results of SEM-EDS shown in Fig. 2, the residue presents several chemical elements, which confer
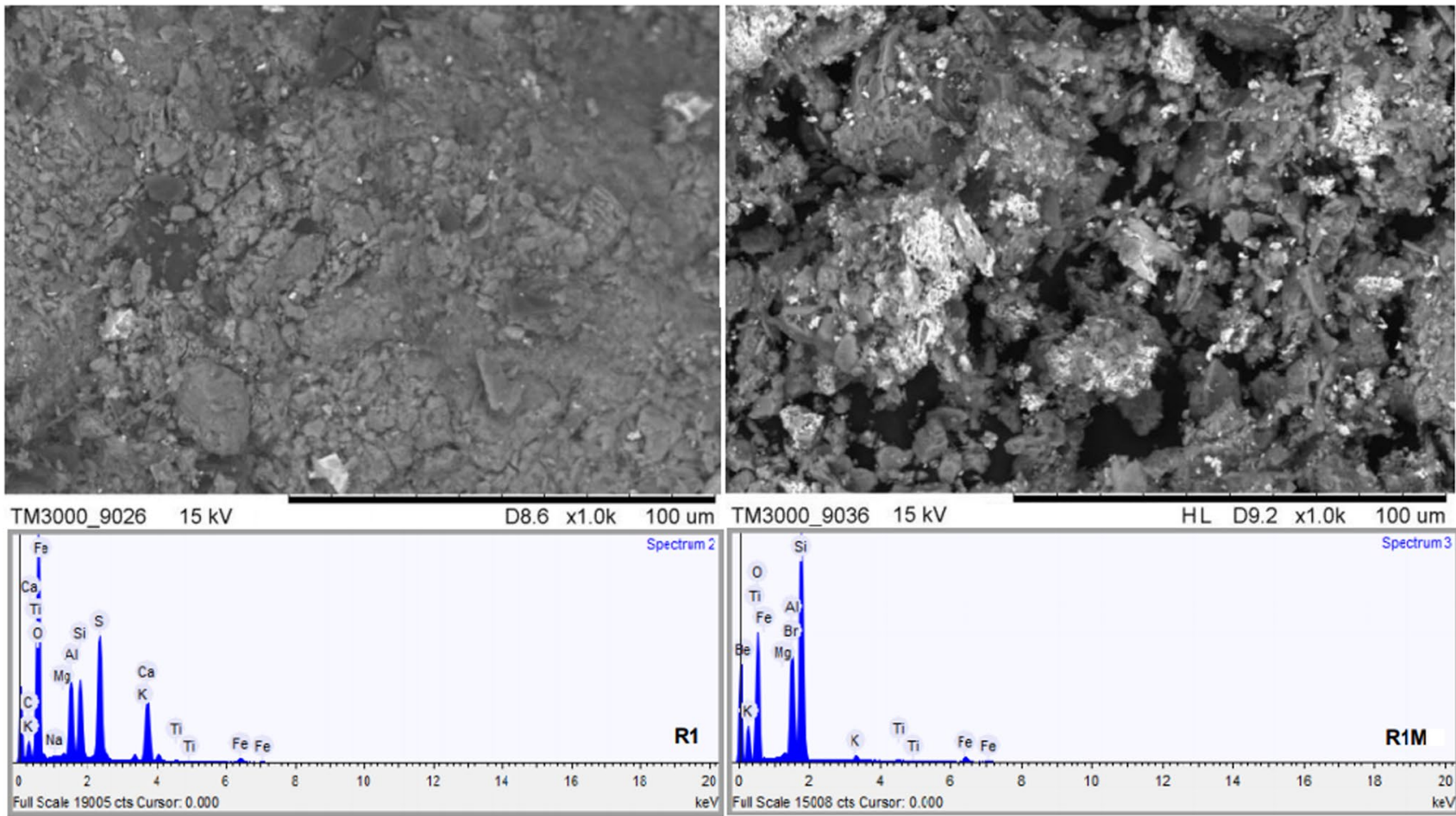

Fig. 2 Image of the SEM/EDS: R1 and R1M

كدينة الملك عبدالعزيز

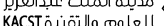


active sites on the adsorbent solid surface with different characteristics. This heterogeneity influences adsorption.

Regarding the element composition presented in Fig. 2, there was a significant increase in the quantity of bromide in the solid R1M and its absence in the remaining solids. The high presence of that element in R1M is probably because the surface chemical modification from the residue with HDTMA-Br was efficient. Regarding the element analysis performed in $\mathrm{R} 1$, the results were pertinent to FRX results, where various oxides were identified, such as $\mathrm{CO}_{2}(37.1 \%)$, $\mathrm{SiO}_{2}(26.0 \%), \mathrm{Al}_{2} \mathrm{O}_{3}(11.6 \%), \mathrm{SO}_{3}(11.3 \%)$ and $\mathrm{Fe}_{2} \mathrm{O}_{3}$ $(11.1 \%)$. Besides this, the oxides of potassium, calcium, magnesium, zinc, titanium, zirconium and strontium were identified at concentrations of $0.01-1 \%$.

Figure 3 presents the X-ray diffraction (XRD) by sample of R1 and R1M.

According to Fig. 3, the crystalline phase is constituted by kaolinite, quartz and sodalite (Yaşar et al. 2018; Zhou et al. 2019). The major component was quartz. It can be seen that the peak intensities were lower for R1M (after the treatment), evidencing a crystallinity decrease.

Figure 4 shows the same peaks in the R1M diffractogram before and after nitrate adsorption.

The X-ray diffraction analysis of natural R1M and R1M after nitrate adsorption is presented in Fig. 4 and shows that the sample after adsorption presents an intensity decrease in some peaks and that others disappear. This can be caused by the replacement of nitrate ions, changing the solid structure.

Figure 5 shows the FTIR spectra with a similar R1M trend before and after nitrate adsorption. Important bands are attributed to $\mathrm{CH}_{3}$ at about wavenumber of $1350 \mathrm{~cm}^{-1}$ and $\mathrm{C}-\mathrm{H}$ at the wavenumber of $900 \mathrm{~cm}^{-1}$ (Cai et al. 2018). The band at about $1700 \mathrm{~cm}^{-1}$ can be associated with the carboxyl group (-COO) (Ren et al. 2016). The several bands at $1000 \mathrm{~cm}^{-1}$ can be ascribed to intercalated surfactant

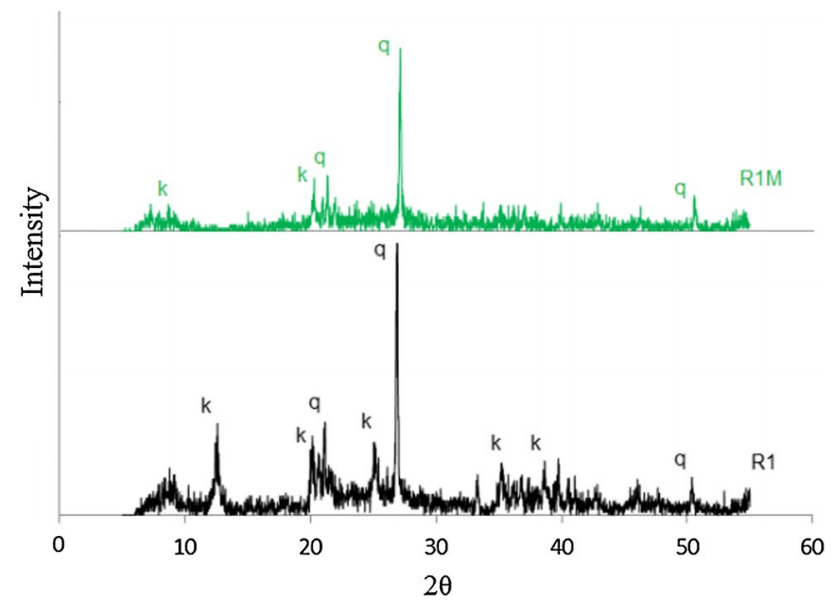

Fig. 3 Results of the XRD analysis of a sample of R1 and R1M. ( $q=$ quartz, $k=$ kaolinite e $s=$ sodalite)

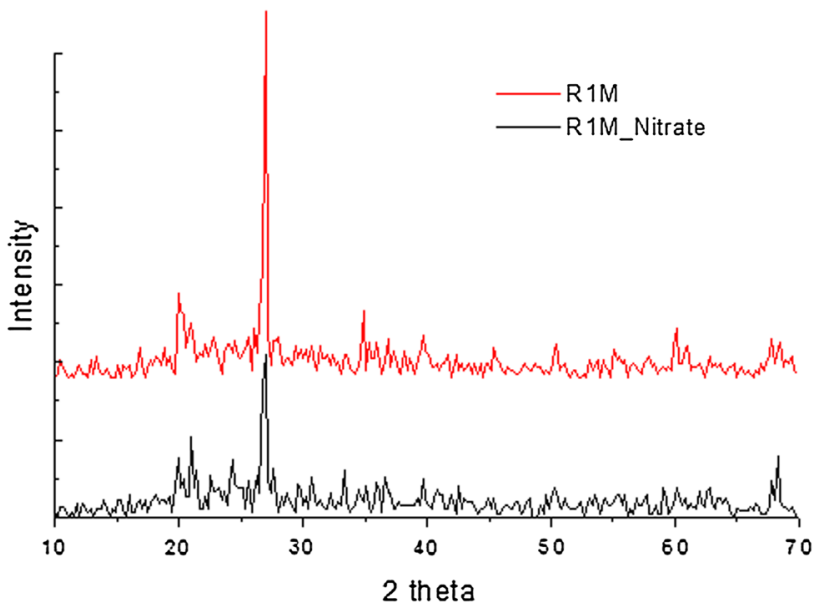

Fig. 4 Results of the XRD analysis of a sample before (R1M) and after adsorption (R1M_Nitrate)

molecules (Frost et al. 2008). In addition, in FTIR analysis, the reduction in principal bans indicates the substitution of $\mathrm{R} 1 \mathrm{M}$ ions for nitrate ions, that is, it indicates an interaction between surface groups on the solid with nitrate.

\section{R1 Surface modification}

The reagent used for surface modification, HDTMA-Br $60 \mathrm{mM}$, is a long-chain quaternary salt of ammonium, which has organic groups covalently bonded to a nitrogen atom, and the positive charge of this atom is neutralized by an anion (bromide). The adsorption process of the surfactant usually occurs only on the external negative surface of solids, mainly by ion exchange and hydrophobic interactions and not by penetration into pores, since the size of the

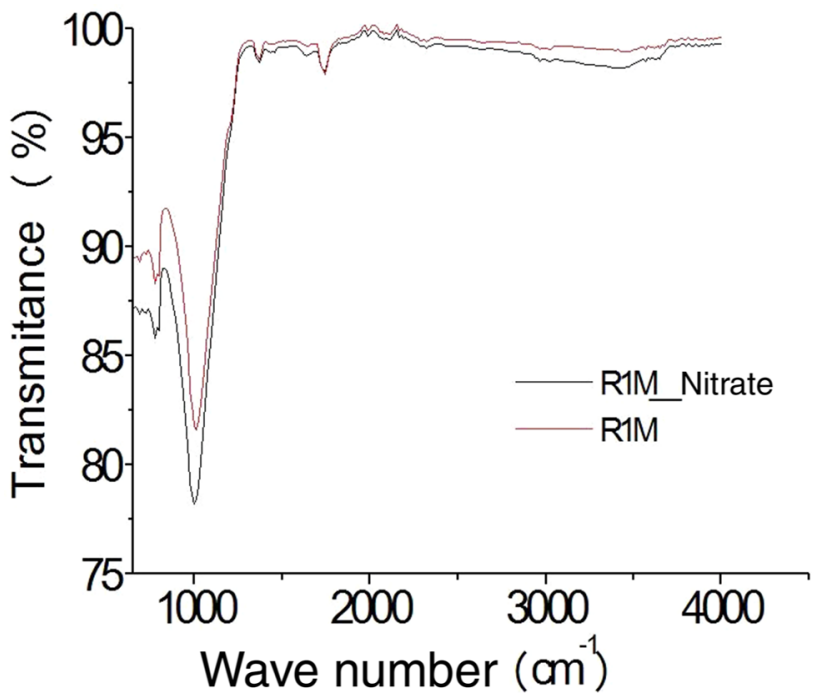

Fig. 5 FTIR spectrums before and after adsorption

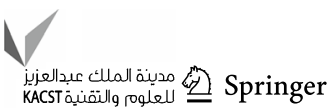




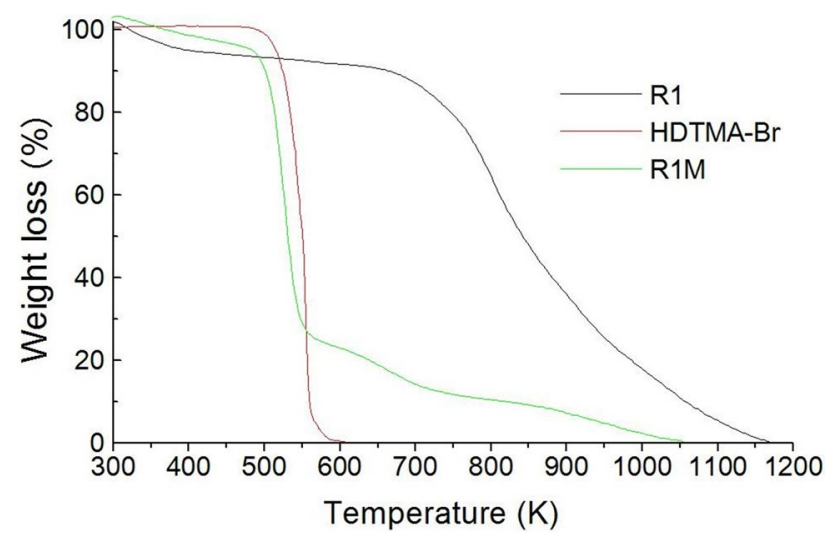

Fig. 6 Curves of TGA analysis. Test conditions: temperature range, 293-1173 K for R1 and R1M and 393 to $632 \mathrm{~K}$ for HDTMA-Br; injector rail heating, $10 \mathrm{~K} \mathrm{~min}^{-1}$; nitrogen gas atmosphere

Table 2 Minimum and maximum quantity of tenside loaded in $\mathrm{R} 1 \mathrm{M}$

\begin{tabular}{ll}
\hline Parameter $X$ & Level \\
\hline Minimum $(y=0)$ & 0.20 \\
Maximum $(y=80)$ & 0.25 \\
\hline
\end{tabular}

molecules of tensoactives is larger than the size of the pores (Xie et al. 2017).

$\mathrm{Xi}$ et al. (2010) performed thermogravimetric studies to characterize clay minerals modified with HDTMA-Br and evaluated the sorption ability of nitrate using this modified solid sorbent. In this study, the authors cited and used Eq. 3 to estimate the maximum and minimum theoretic quantity of tenside that effectively adhered to clay minerals:

$X=\frac{S .10^{5}}{76.4(M-y)(100-S)}$,

where $X=$ quantity of tenside loaded per gram of solid, $M=$ molecular weight of tenside ( $364.45 \mathrm{~g}$ ), $S=$ mass loss of tenside in solid (\%), $y=0$ (if all ions of $\mathrm{Br}$ remained) or 80 (if no $\mathrm{Br}$ ion remained), molecular weight $\mathrm{Br}=80 \mathrm{~g}$.

According to the aforementioned authors, TGA tests were performed aiming to obtain the maximum and minimum values of tensoactives that could be loaded in order to optimize the initial concentration of HDTMA-Br used. Figure 6 shows the curves of TGA analysis performed in the samples $\mathrm{R} 1, \mathrm{R} 1 \mathrm{M}$ and in the reagent HDTMA-Br.

In the HDTMA-Br graph shown in Fig. 6, the loss of mass characteristic to the reagent occurred between 473 and $573 \mathrm{~K}$, a temperature similar to the one obtained by $\mathrm{Xi}$ et al. (2010). By observing the R1M graph, it is acceptable to state that the loss of mass ( $S=5.17 \%$ ) was caused by decomposition of the tenside. Using Eq. 1 with $y=0$ and $y=80$, the results of the maximum and minimum amounts of tenside that may be provided can be obtained (Table 2).

Considering that the added value of the agent equals approximately $2.4 \mathrm{CEC}$ of the solid and that the quantity that was able to be effectively loaded $(0.20-0.25)$ was below the theoretical value, it was estimated that, with a solution of $60 \mathrm{mM}$ HDTMA-Br, the surface modification would already be efficient, resulting in a tenfold reduction in the amount of reagent used to modify the solid surface.

\section{Adsorption parameters influence and determination of ideal conditions}

Figure 7 shows the effects of $\mathrm{pH}$ on the adsorption test performed with the solid R1 and R1M.

According to data shown in Fig. 7, the coal tailing (R1) is not efficient for nitrate removal. A different behavior was found for R1M, showing that the particle superficial modification was effective for the process. The $\mathrm{pH} 6$ was found to provide the best results.

The $\mathrm{pH}$ of maximum efficiency found in this study is similar as results found by other authors who used solid wastes to adsorb nitrate. Öztürk and Bektaş (2004) evaluated nitrate removal using slags of sepiolite and activated sepiolite with hydrochloric acid as adsorbents. The authors considered that the nitrate removal was not significantly affected by $\mathrm{pH}$ variation, even though a higher ion removal occurred at pH 6. On the other hand, Xi et al. (2010) used clay mineral waste (bentonite, kaolinite and halloysite) modified with HDTMA-Br solution for nitrate removal by sorption and the pH used was 5.4. Cho et al. (2011) evaluated the $\mathrm{pH}$ influence by using coal chemically modified by trimethylammonium chloride and found that there was a decrease in nitrate removal with an increase in $\mathrm{pH}$ from 3 to 6 . However, in tests where the $\mathrm{pH}$ was greater than 6 , the sorption ability did not increase. According to the authors, the electrostatic interaction decreases with $\mathrm{pH}$ increase and other interactions began to act on the nitrate removal. The ionic exchange between chloride and nitrate is the only indirect evidence of this.

The results found for residence time are shown in Fig. 8.

In Fig. 8, nitrate removal remained stable from $60 \mathrm{~min}$, tending to a slight decrease. Thus, the time considered ideal for the test of nitrate adsorption using the $\mathrm{R} 1 \mathrm{M}$ was $60 \mathrm{~min}$, where the ion concentration went from 15 to $3.74 \mathrm{mg} \mathrm{L}^{-1}$ with about $75 \%$ of removal. However, in order to ensure the kinetic balance of the system, in the tests carried out for modeling the adsorption isotherms, the contact time was $80 \mathrm{~min}$.

Figure 9 shows the effects of sorbent concentration on nitrate removal. 

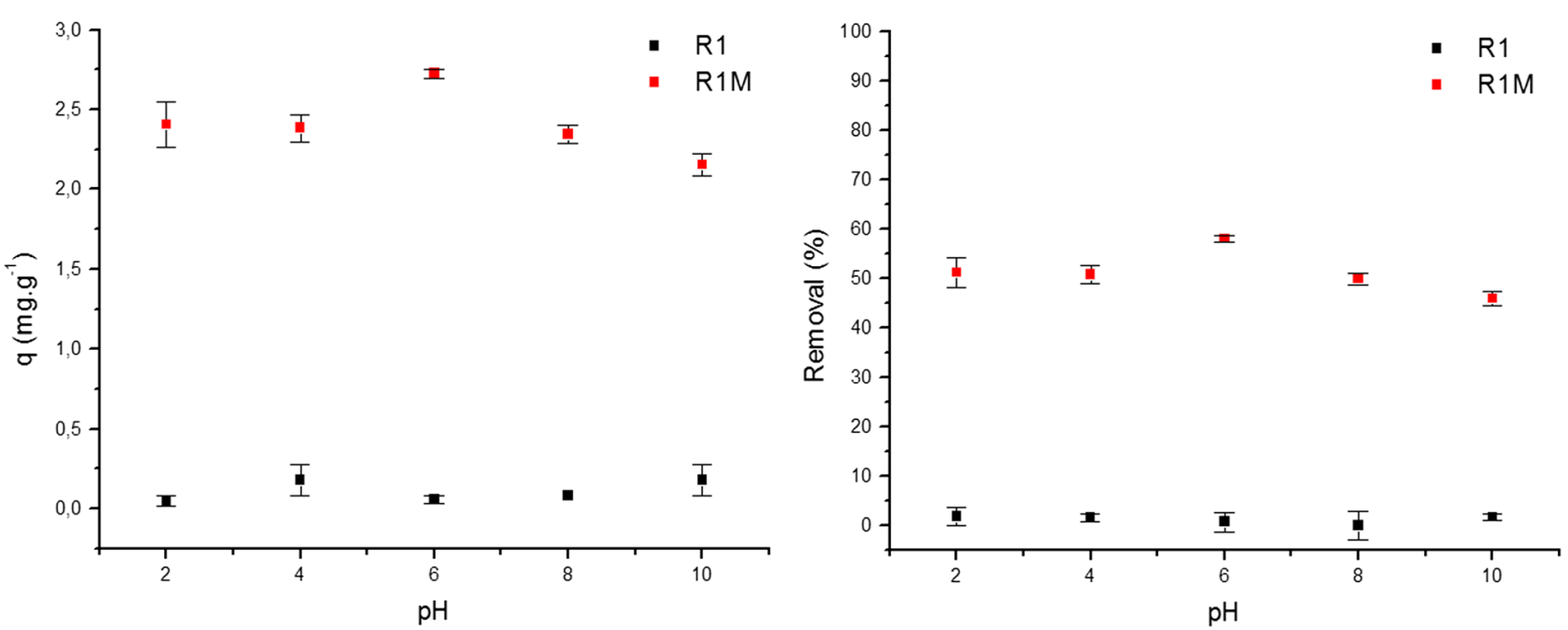

Fig. 7 Effect of $\mathrm{pH}$ on the adsorption of nitrate using R1 and $\mathrm{R} 1 \mathrm{M}$ as sorbent. Experimental conditions: initial concentration of the solution, $15 \mathrm{mg} \mathrm{L}^{-1}$ of $\mathrm{NO}_{3}^{-}$; residence time, $30 \mathrm{~min}$; solid concentration, $0.5 \mathrm{~g} 100 \mathrm{~mL}^{-1}$
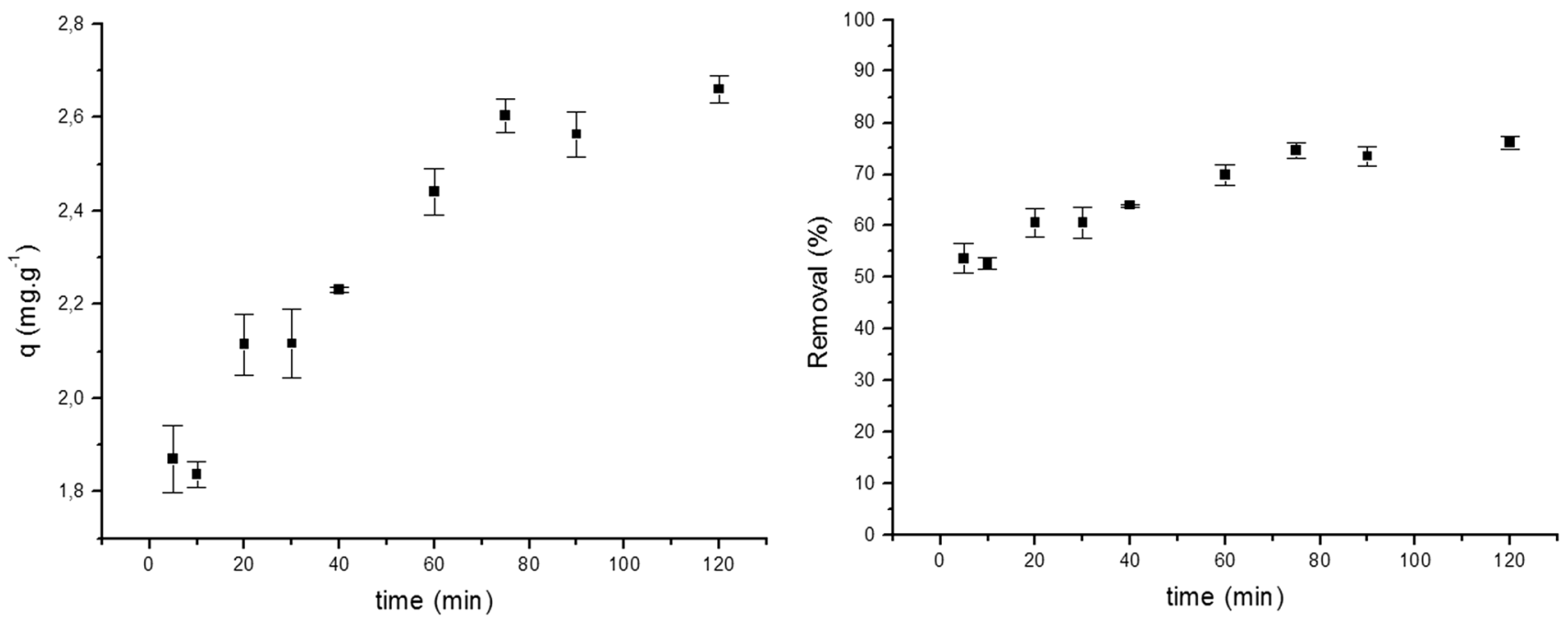

Fig. 8 Effect of residence time on nitrate adsorption using R1M as sorbent. Experimental conditions: initial concentration of the solution, $15 \mathrm{mg} \mathrm{L}^{-1}$ of $\mathrm{NO}_{3}^{-}$; initial $\mathrm{pH}, 6$; solid concentration, $0.5 \mathrm{~g} 100 \mathrm{~mL}^{-1}$

Nitrate removal stabilizes at approximately $90 \%$ with a concentration of solid sorbent at $10 \mathrm{~g} \mathrm{~L}^{-1}\left(1 \mathrm{~g} .100 \mathrm{~mL}^{-1}\right)$.

Considering the results, the parameters of nitrate adsorption in aqueous solution using $\mathrm{R} 1 \mathrm{M}$ as adsorbent were $\mathrm{pH}$, residence time of $60 \mathrm{~min}$ and concentration of solid sorbent $10 \mathrm{~g} \mathrm{~L}^{-1}$.

\section{Adsorption kinetics}

To understand the dynamic interactions of nitrate with coal residues and to predict their behavior with time, knowledge of the kinetics of these processes is important. The calculated parameters of kinetic models and correlation coefficients $\left(R^{2}\right)$ are shown in Table 3.

The calculated kinetic model parameters and correlations are shown in Table 3. The pseudo-first-order and pseudo-second-order models have determination coefficient values of 0.9191 and 0.9599 , respectively. Thus, the model that best adjusted to experimental data showed a strong relation between parameters, indicating that the process can be described by pseudo-second-order kinetics. The coal residue qe values were 2.6606. This value is close to the amount of solute adsorbed with a value of $2.5384 \mathrm{mg} \mathrm{L}^{-1}$. This model suggests that the chemisorption process could be a rate-limiting step and 

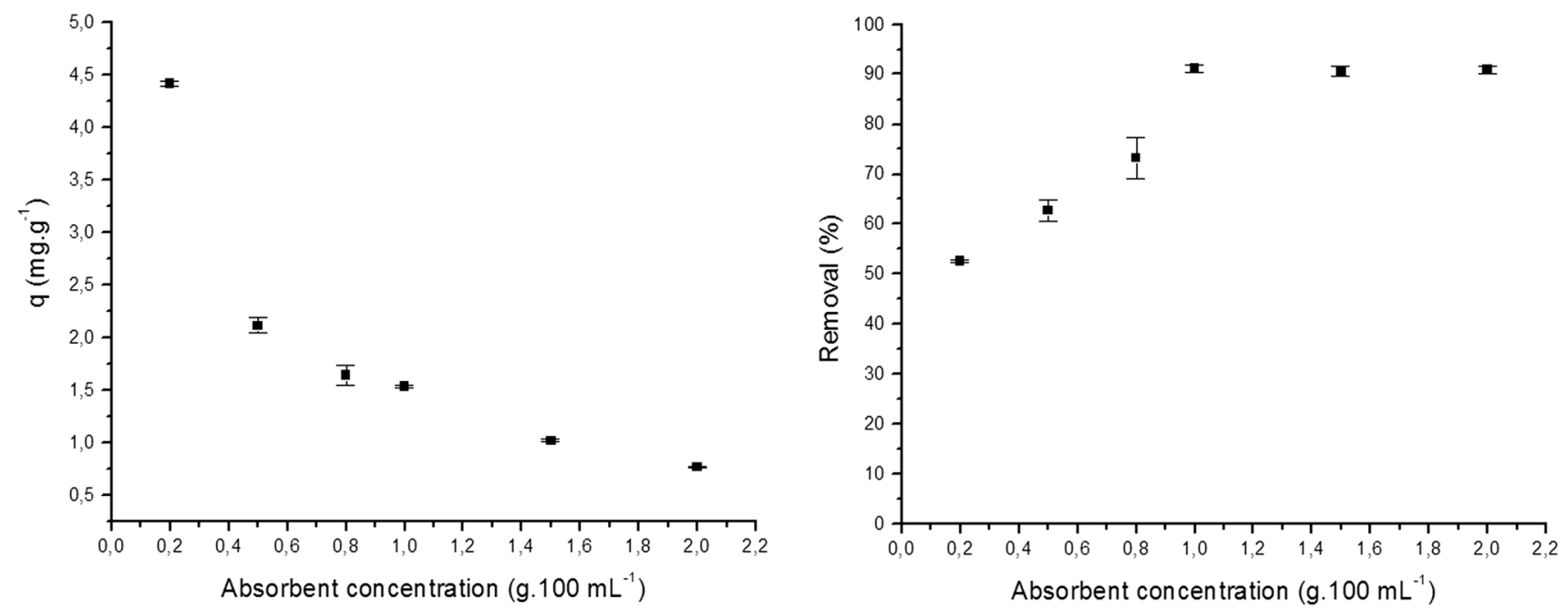

Fig. 9 Effect of solid concentration R1M on the nitrate adsorption. Experimental conditions: initial concentration of the solution, $15 \mathrm{mg} \mathrm{L}^{-1}$ of $\mathrm{NO}_{3}^{-}$; initial $\mathrm{pH}$, natural; residence time, $30 \mathrm{~min}$

Table 3 Calculated parameters of the pseudo-first-order and pseudo-second-order kinetic models for adsorption of nitrate over coal beneficiation residue

\begin{tabular}{lll}
\hline Experimental data & Pseudo-first-order model & Pseudo-second-order model \\
\hline Qe $\left(\mathrm{mg} \mathrm{g}^{-1}\right) 2.6606$ & $q_{1}\left(\mathrm{mg} \mathrm{g}^{-1}\right) 2.4049$ & $q_{2}\left(\mathrm{mg} \mathrm{g}^{-1}\right) 2.5384$ \\
& $k_{1}\left(\mathrm{~min}^{-1}\right) 0.2540$ & $k_{2}\left(\mathrm{~min}^{-1}\right) 8.5550$ \\
& $R^{2} 0.9191$ & $R^{2} 0.9599$
\end{tabular}

adsorption process may involve electrostatic attraction, anion exchange and chemical bonding (Shan et al. 2015). The same model was chosen for the adsorption of nitrate in other studies (Öztürk and Bektaş 2004; Chabani et al. 2007; Katal et al. 2012).

\section{Isotherms of adsorption balance}

Sorption isotherms were drawn at 398, 308 and $318 \mathrm{~K}$ using the operational conditions found in the previous item (initial $\mathrm{pH}$, residence time of $80 \mathrm{~min}$ and concentration of solid sorbent $10 \mathrm{~g} \mathrm{~L}^{-1}$ ). The experimental data are adjusted to the isotherm models of Langmuir, Freundlich and Sips.

The Langmuir isotherm is a model that assumes that adsorption is homogeneous and that molecule adsorption occurs in a fixed and defined number of sites, all able to adsorb a single molecule at a time without interacting with the molecules adsorbed by neighboring sites, according to Eq. 4 (Langmuir 1918).

$Q_{e}=q_{e \max } \frac{K_{L} C_{e}}{1+K_{L} C_{e}}$, where $Q_{e}=$ amount sorbed at equilibrium, $\mathrm{mg} \mathrm{g}^{-1}$, $q_{e \max }=$ constant of maximum sorption capacity, $\mathrm{mg} \mathrm{g}^{-1}$, $K_{L}=$ constant of Langmuir related to the energy of sorption, $\mathrm{L} \mathrm{mg}^{-1}$, and $C_{e}=$ ion concentration in equilibrium, $\mathrm{mg} \mathrm{L}^{-1}$

Thus, the $R_{L}$ separation factor can be calculated by Eq. 5, where under a value of $R_{L}>1$, the isotherm will be considered unfavorable or favorable when $0<R_{L}<1$.

$R_{L}=\frac{1}{1+K_{L} C_{0}}$,

where $K_{L}=$ constant of Langmuir related to the sorption energy, $\mathrm{L} \mathrm{mg}^{-1}$, and $\mathrm{C}_{0}=$ initial adsorbate concentration, $\mathrm{mg} \mathrm{L}^{-1}$

On the other hand, the Freundlich isotherm allows describing the favorable or unfavorable adsorption and considers the formation of multiple layers with a nonuniform distribution of adsorption and affinities on the heterogeneous surface (Foo and Hameed 2010; Freundlich 1906). Equation 6 describes the Freundlich isotherm:

$Q_{e}=K_{F} C_{e}^{1 / n}$

where $Q_{e}=$ amount of adsorbate in the adsorbent in balance, $\mathrm{mg} \mathrm{g}^{-1}, K_{F}=$ constant related to the adsorption capacity 
$\left(\mathrm{mg} \mathrm{g}^{-1}\right) .\left(\mathrm{L} \mathrm{mg}^{-1}\right)^{n}, C_{e}=$ concentration in equilibrium, $\mathrm{mg} \mathrm{L}^{-1}, n=$ empirical parameter related to the intensity of adsorption or heterogeneity of the surface, where the surface of the solid sorbent is more heterogeneous whenever its value approaches zero. Therefore, values of $1 / n$ within the range $0.1<1 / n<1$ represent favorable sorption conditions.

Another model evaluated in this study was the isotherm of Sips, which is a combination of the two isotherms described above (Langmuir and Freundlich), represented by Eq. 7. This isotherm considers the heterogeneity of the adsorbent's surface and the interactions between adsorbed molecules (Tóth 2001).

$Q_{e}=q_{e \max } \frac{K_{L} C_{e}^{n}}{1+K_{L} C_{e}^{n}}$,

Fig. 10 Adsorption isotherms 298 K. Experimental conditions: initial $\mathrm{pH}, 6$; solid concentration, $1 \mathrm{~g} 100 \mathrm{~mL}^{-1}$, residence time, $80 \mathrm{~min}$; rotation, $150 \mathrm{rpm}$

Fig. 11 Adsorption isotherms 308 K. Experimental conditions: initial $\mathrm{pH}, 6$; concentration of solid, 1 g. $100 \mathrm{~mL}^{-1}$; residence time, $80 \mathrm{~min}$; shake, $150 \mathrm{rpm}$ where $Q_{e}, q_{e \max }$ and $K_{L}$ have the same meaning as in the Langmuir isotherm. $n=$ empirical parameter that indicates the heterogeneity of the adsorbent. When $n=1$, the model reduces to the Langmuir isotherm.

Figures 10, 11 and 12 show a comparison between the adsorption experimental equilibrium data and the values predicted by Freundlich, Sips and Langmuir isotherm models at the temperatures of 298, 308 and $318 \mathrm{~K}$, respectively.

According to the analysis of data and models plotted in Figs. 10, 11 and 12, the Langmuir model fits the experimental data the least at all temperatures evaluated. The other two models (Freundlich and Sips) described better the behavior of experimental data.

The curves obtained in this study are similar to the type-S isotherm curve cited by Giles et al. (1974). The type-S isotherm is characterized by an initial slope with a tendency to
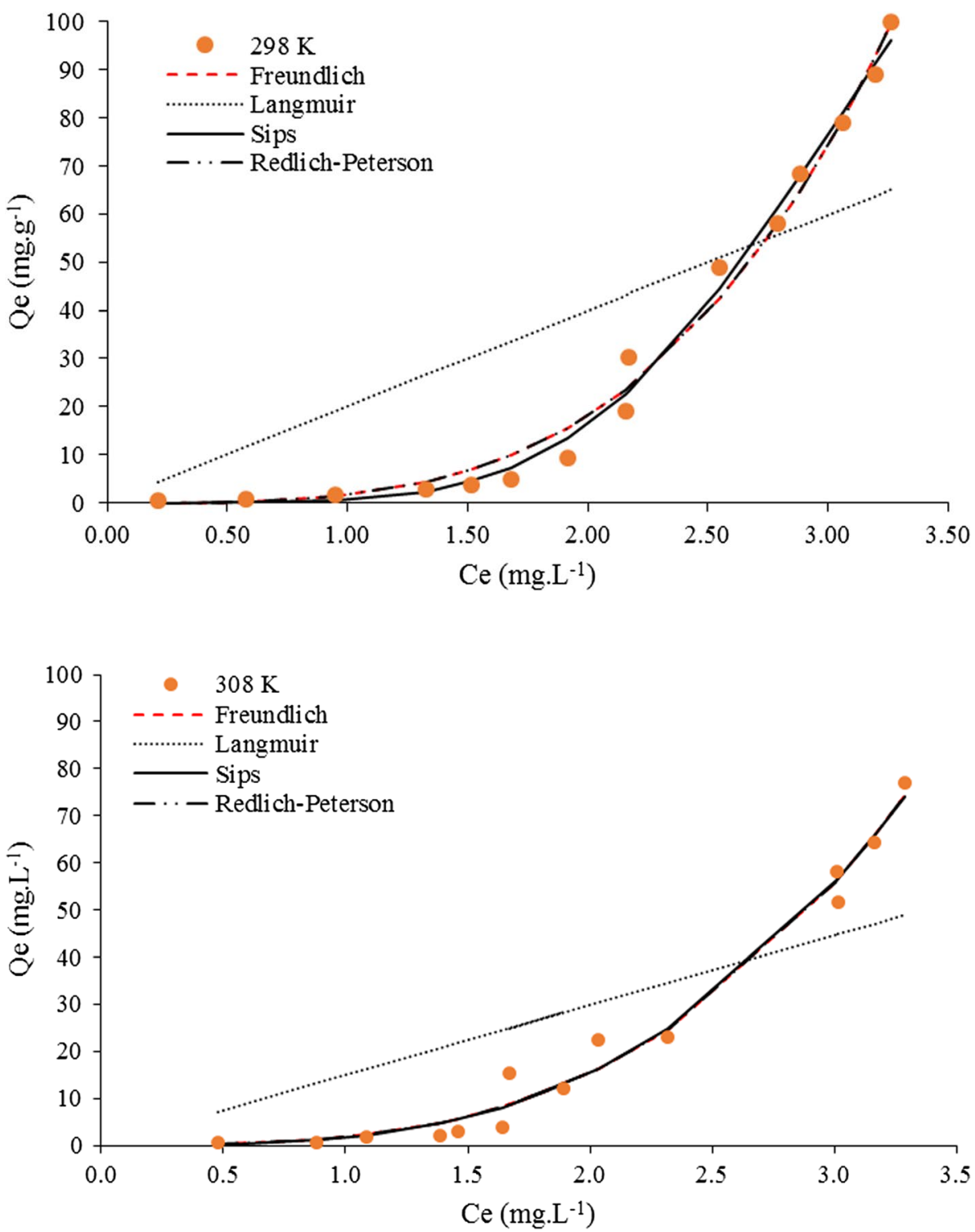
Fig. 12 Adsorption isotherms $318 \mathrm{~K}$. Test conditions: initial $\mathrm{pH}, 6$; concentration of solid, $1 \mathrm{~g} 100 \mathrm{~mL}^{-1}$; residence time, $80 \mathrm{~min}$; shake, $150 \mathrm{rpm}$

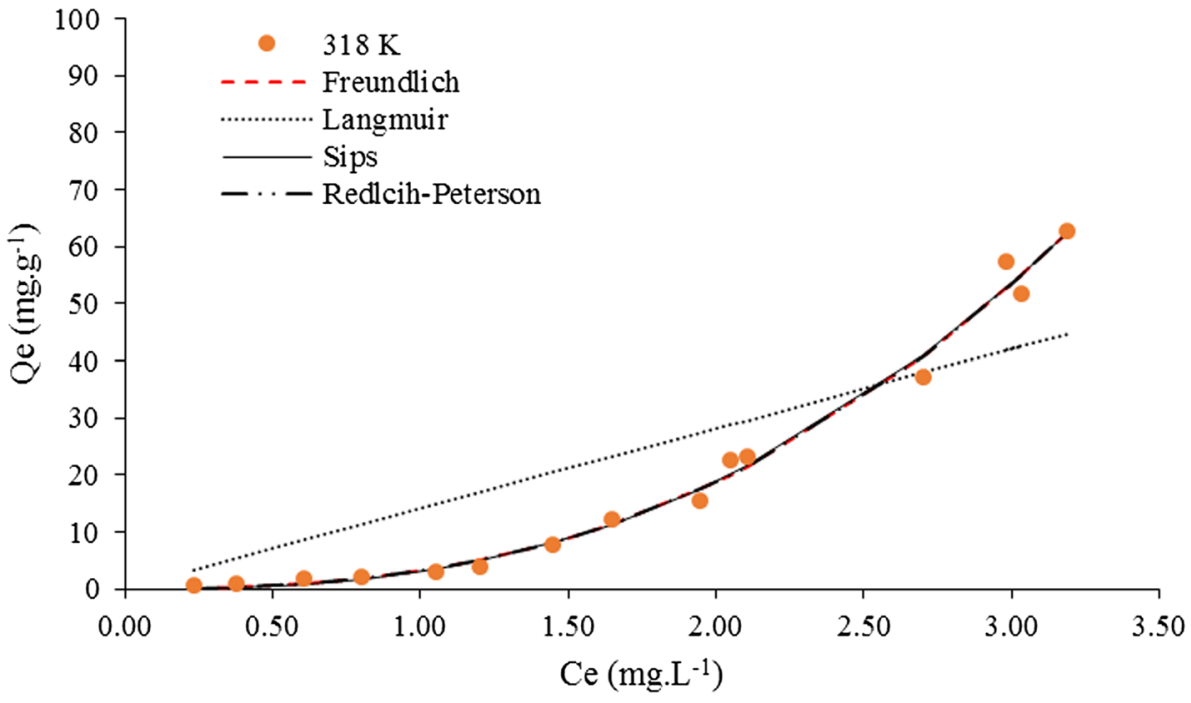

Table 4 Parameters of Freundlich, Langmuir and Sips isotherms at 298,308 and $318 \mathrm{~K}$

\begin{tabular}{|c|c|c|c|c|}
\hline & Parameters & $298 \mathrm{~K}$ & $308 \mathrm{~K}$ & $318 \mathrm{~K}$ \\
\hline \multirow[t]{4}{*}{ Freundlich } & $\mathrm{R}^{2}$ & 0.9898 & 0.9833 & 0.9908 \\
\hline & $K_{F}$ & 1.6224 & 1.7181 & 3.1364 \\
\hline & $n$ & 0.2874 & 0.3162 & 0.3876 \\
\hline & Error & 0.392 & 0.475 & 0.207 \\
\hline \multirow[t]{4}{*}{ Langmuir } & $R^{2}$ & 0.6473 & 0.6417 & 0.757 \\
\hline & $q_{e \text { máx }}$ & 5429.67 & 5429.68 & 5429.64 \\
\hline & $K_{L}$ & 0.0037 & 0.0028 & 0.0026 \\
\hline & Error & 12.43 & 10.182 & 5.436 \\
\hline \multirow[t]{5}{*}{ Sips } & $R^{2}$ & 0.992 & 0.9834 & 0.9909 \\
\hline & $q_{e \text { máx }}$ & 191.823 & 1074.712 & 1036.39 \\
\hline & $K_{L}$ & 0.3064 & 0.1368 & 0.1116 \\
\hline & $n$ & 4.8673 & 3.2641 & 2.6616 \\
\hline & Error & 0.265 & 0.481 & 0.207 \\
\hline
\end{tabular}

become vertical with increasing solute concentrations in the solution and consequent increases in sorbed molecules, suggesting that, at low concentrations, the affinity between sorbent and sorbate is lower than the affinity between solute and solvent. The type-S isotherm has a low initial adsorption and increases as the number of adsorbed molecules increases. This means that, according to Giles et al. (1974), there is an association between adsorbed molecules, which is called cooperative adsorption, i.e., the sorbate has a low affinity with the sorbent solid, but as soon as the surface of the solid is covered by sorbate, other molecules of this compound are adsorbed more easily. In cooperative adsorption, there is an interaction between adsorbate species favoring the adsorption on the adsorbent surface since the adsorbate has difficulty in accessing the pores of the adsorbent (Atkins 1970).
Table 4 lists the isotherm model parameters at the temperatures of 298,308 and $318 \mathrm{~K}$, as well as the correlation coefficient and the error between the experimental value and predicted value for each model. According to the data, they best fit the model described by Sips at a temperature of 298 K, with $R^{2}=0.9925$.

The parameters obtained using the Langmuir model confirm that this isotherm fits less the experimental data. Besides the low correlation, the error obtained was the largest in the present study.

By assessing the parameters of the Freundlich isotherm, an increasing temperature also increases the value of $K_{F}$. This parameter is very important because it is related to adsorption capacity: the higher this value, the greater the adsorption. With the parameter $n$ close to zero, the surface heterogeneity of the solid sorbent R1M, which was visualized in SEM images, is confirmed. Also related to the value of $n$, the sorption occurred under unfavorable conditions, as $1 / n$ is outside the range $0.1<1 / n<1$ representing favorable conditions. Finally, it is possible to confirm the cooperative adsorption in the system nitrate/R1M in the adsorbent's active sites with different bond energies, since the value of $n$ in Freundlich parameters was below 1 (Atkins 1970).

According to Fig. 13, as the temperature increases, the maximum adsorbed amount decreases from about $90 \mathrm{mg} \mathrm{g}^{-1}$ in the lower evaluated temperature to just over $60 \mathrm{mg} \mathrm{g}^{-1}$ at the highest temperature.

The amount of substance adsorbed on the surface decreases with increasing temperature, since the adsorption processes are generally exothermic. It is known that when reducing the temperature of the solution, the compound molecules generally lose energy and consequently mobility, thus favoring the formation of the adsorbed complex (Freundlich 1906). 
Fig. 13 Experimental isotherms at 298, 308 and $318 \mathrm{~K}$. Test conditions: initial $\mathrm{pH}, 6$; solid

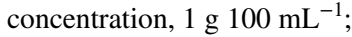
residence time, $80 \mathrm{~min}$; agitation, $150 \mathrm{rpm}$

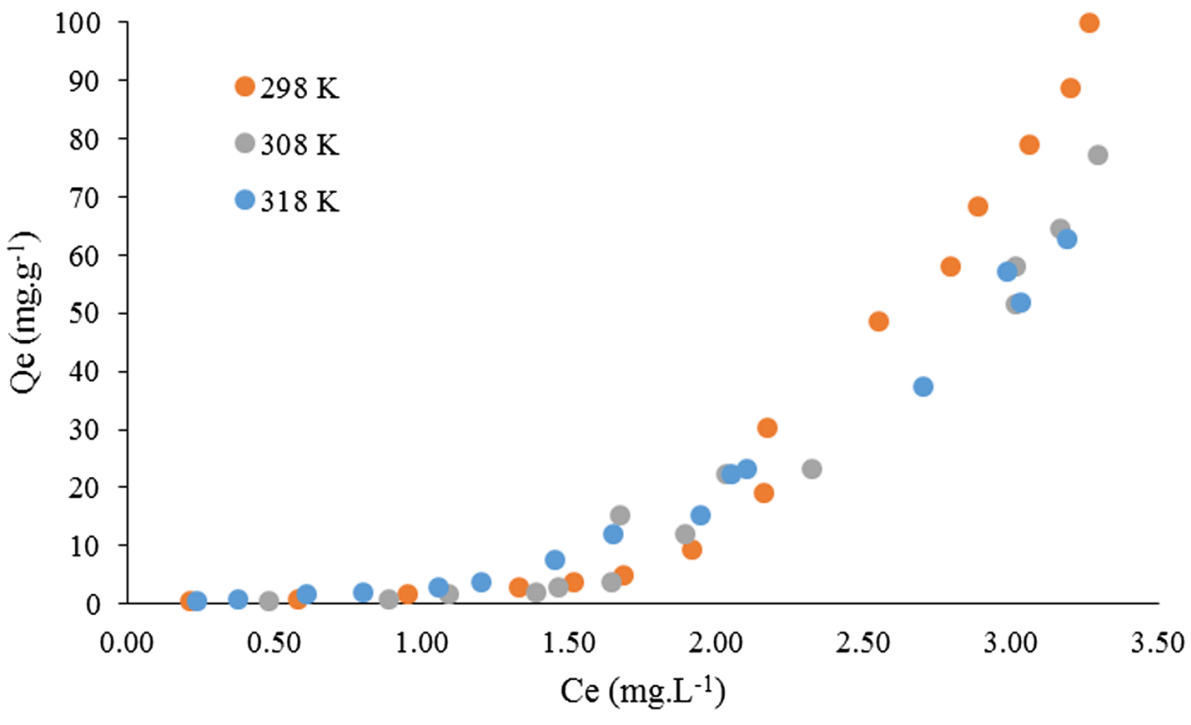

Table 5 Thermodynamic parameters by nitrate removal on R1M solid

\begin{tabular}{lccc}
\hline & \multicolumn{1}{c}{$298 \mathrm{~K}$} & \multicolumn{1}{c}{$308 \mathrm{~K}$} & $318 \mathrm{~K}$ \\
\hline $\mathrm{K}_{\mathrm{L}}\left(\mathrm{L} \mathrm{mg}^{-1}\right)$ & 0.3064 & 0.1368 & 0.1116 \\
$\mathrm{~K}_{\mathrm{L}}\left(\mathrm{L} \mathrm{mol}^{-1}\right)$ & 18998.33 & 8482.284 & 6919.758 \\
$\Delta \mathbf{G}^{\circ}\left(\mathrm{kJ} \mathrm{mol}^{-1}\right)$ & -24.4093 & -23.1635 & -23.3773 \\
$\Delta \mathbf{H}^{\circ}\left(\mathrm{kJ} \mathrm{mol}^{-1}\right)$ & -40.02942 & -40.02942 & -40.02942 \\
$\Delta \mathbf{S}^{\circ}\left(\mathrm{kJ}\left(\mathrm{mol} \mathrm{K}^{-1}\right)\right.$ & -53.1788 & -53.1788 & -53.1788 \\
\hline
\end{tabular}

Sips was the model that best described the experimental data at the three temperatures, with $R^{2}$ values of 0.9925 , 0.9834 and 0.9909 for 298,308 and $318 \mathrm{~K}$, respectively. This isotherm model relates the Langmuir and Freundlich equations and predicts the systems of heterogeneous adsorption and works around the limitation of the adsorbate concentration associated with Freundlich isotherm.

\section{Thermodynamic of adsorption}

The adsorption thermodynamics is necessary for the study to reveal the inherent energy change of adsorbent after adsorption and the mechanism involved in the adsorption process. The thermodynamic parameters were determined by Gibbs free energy (8) and Van't Hoff Eq. (9):

$\Delta \mathrm{G}^{\circ}=-\mathrm{RT} \ln \mathrm{k}$

$\ln \mathrm{k}=\frac{-\Delta \mathrm{H}^{\circ}}{\mathrm{RT}}+\frac{\Delta \mathrm{S}^{\circ}}{\mathrm{R}}$

where $\Delta G^{\circ}$ is the Gibb's free energy, $R$ is the universal constant of ideal gases, whose value is $8.314 \mathrm{~J} \mathrm{~mol}^{-1} \mathrm{~K}^{-1}$, $T$ is the temperature in Kelvin, $K$ is the fitted constant of isotherm model (dimensionless), $\Delta H^{\circ}$ is enthalpy and $\Delta S^{\circ}$ is entropy.

The Van't Hoff equation measures changes in the equilibrium constant with variations in temperature and can be obtained by the thermodynamics parameters from the intercept and slope calculated by a plot of $\operatorname{Ln}(k)$ versus $T^{-1}$, respectively. The equation obtained was $y=4.8147 x-6.3963$, with $R^{2}$ of 0.9051 . These values were used to find the parameters shown in Table 5.

The results show that the process mechanism was satisfactory because $\Delta G^{0}$ values were negative for all temperatures, regarding the solid, resulting in a spontaneous process. The $\Delta G^{\circ}$ values for nitrate removal increased with an increase in temperature, showing that the process is less spontaneous at higher temperatures. The enthalpy values were negative, revealing an exothermic process. This is supported by the decrease in nitrate removal from the solid with an increase in temperature, as shown in Fig. 13. The entropy values were also negative and irreversible. Therefore, the thermodynamic parameters suggest a spontaneous, exothermic and irreversible process for nitrate removal on the R1M solid. The results showed chemisorption phenomena, and this behavior is according to kinetic results, which showed a pseudo-second-order model and are similar to other studies in the literature.

$\mathrm{Hu}$ et al. (2015) reported nitrate removal on granular chitosan- $\mathrm{Fe}^{3+}$, where the point of zero charge was obtained at $\mathrm{pH} 5$ and the maximum adsorption capacity and adsorption process followed the pseudo-second-order kinetic model. The experimental equilibrium data fitted the Langmuir-Freundlich and thermodynamic parameters and revealed that nitrate adsorption was a spontaneous and exothermic process.

Fan and Zhang (2018) reported on adsorbents from raw corn stalks. They studied adsorption characteristics

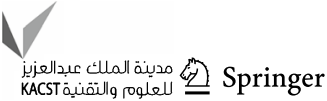


Table 6 Concentration of each analyzed component in the gross sample, after adsorption test and the percentage removal

\begin{tabular}{lccc}
\hline Component & \multicolumn{2}{c}{ Concentration $\left(\mathrm{mg} \mathrm{L}^{-1}\right)$} & Removal (\%) \\
\cline { 2 - 3 } & Gross sample & $\begin{array}{l}\text { Sample after } \\
\text { adsorption }\end{array}$ \\
\hline Bromide & 0.04 & 134.82 & - \\
Chloride & 19.92 & 17.15 & 13.91 \\
Fluoride & 0.29 & 0.27 & 4.97 \\
Nitrate & 7.81 & 0.51 & 93.47 \\
Nitrite & 0.19 & 0.07 & 62.91 \\
Sulfate & 17.28 & 16.80 & 2.78 \\
\hline
\end{tabular}

of nitrate and phosphate on this solid. The pseudo-second-order kinetics equation and Langmuir isotherm could describe the adsorption process, and the maximum adsorption capacities $(298 \mathrm{~K})$ of nitrate and phosphate on the solid, as calculated from the Langmuir isotherm, were 13.6054 and $22.8833 \mathrm{mg} \mathrm{g}^{-1}$, respectively. The obtained thermodynamic parameters indicated a spontaneous and exothermic nature of adsorption.

\section{Real wastewater test}

Table 6 shows the concentration of each analyzed component in the gross sample after adsorption test and percentage removal.

According to the results shown in Table 6, nitrate and nitrite anions and cations obtained the highest removal among all compounds, $93.5 \%$ and $62.9 \%$, respectively. The increase in bromide concentration is consistent with excess surfactant agent in tailing coal modifier solution. The bromide together with the HDTMA-Br agent can release from the solid and dilute in the solution where the adsorption process occurs.

\section{Conclusion}

After the adsorption process, the tailing may be sent to Landfill of Hazardous Industrial Waste. The adsorption process for effluent treatment generates a low volume of waste compared to the conventional process. However, this treatment can be considered advantageous.

After a preliminary test, the coal beneficiation tailing R1 is not efficient as a sorbent for nitrate removal. The modification performed using HDTM-Br enhanced the surficial characteristics of the solid, and nitrate removal levels over $90 \%$ were found. The results show that the most suitable experimental conditions for batch adsorption were $\mathrm{pH} 6$, contact time of $60 \mathrm{~min}$ and $1 \mathrm{~g} 100 \mathrm{~mL}^{-1}$ of solid. The kinetic model that best adjusted to the experimental was pseudo-second order. Adsorption isotherms were constructed at three different temperatures $(298,308$ and $318 \mathrm{~K})$, and the model that best described the process behavior was Sips, achieving a $\mathrm{R}^{2}$ greater than 0.99 at all temperatures.

By applying these conditions to a real wastewater, a 93\% nitrate removal is obtained. Comparing the results obtained with the Resolution no. 357 of CONAMA 2005, which provides for the classification of water bodies and establishes the conditions and patterns of effluent disposal in Brazil, the effluent, after treatment with the studied adsorption process, reached the limit established by the resolution.

Funding Non-funding

\section{Compliance with ethical standards}

Conflict of interest The authors declare that they have no conflict of interest.

Open Access This article is licensed under a Creative Commons Attribution 4.0 International License, which permits use, sharing, adaptation, distribution and reproduction in any medium or format, as long as you give appropriate credit to the original author(s) and the source, provide a link to the Creative Commons licence, and indicate if changes were made. The images or other third party material in this article are included in the article's Creative Commons licence, unless indicated otherwise in a credit line to the material. If material is not included in the article's Creative Commons licence and your intended use is not permitted by statutory regulation or exceeds the permitted use, you will need to obtain permission directly from the copyright holder. To view a copy of this licence, visit http://creativecommons.org/licenses/by/4.0/.

\section{References}

ABNT - ASSOCIAÇÃO BRASILEIRA DE NORMAS TÉCNICAS, NBR 10004:2004: Resíduos sólidos: Classificação (2004) $2^{\mathrm{a}}$ edição. 71

Alaburda J, Nishihara L (1998) Presença de compostos de nitrogênio em águas de poços. Revista Saúde Pública 32:160-165. https:// doi.org/10.1590/S0034-89101998000200009

Al-Ghouti MA, Al-Kaabi MA, Ashfaq MY, Da'na DA (2019) Produced water characteristics, treatment and reuse: a review. J Water Process Eng 28:222-239. https://doi.org/10.1016/j.jwpe.2019.02.001

Atkins P (1970) Physical chemistry. Oxford University Press, Oxford

Bhatnagar A, Sillanpää M (2011) A review of emerging adsorbents for nitrate removal from water. Chem Eng J 168:493-504. https://doi. org/10.1016/j.cej.2011.01.103

Cai Y, Du M, Wang S, Liu L (2018) Flotation characteristics of oxidized coal slimes within low-rank metamorphic. Powder Technol 340:34-38. https://doi.org/10.1016/j.powtec.2018.09.006

Cecconet D, Zou S, Capodaglio AG, He Z (2018) Evaluation of energy consumption of treating nitrate-contaminated groundwater by bioelectrochemical systems. Sci Total Environ 636:881-890. https:// doi.org/10.1016/j.scitotenv.2018.04.336

Chabani M, Amrane A, Bensmaili A (2007) Kinetics of nitrates adsorption on Amberlite IRA 400 resin. Desalination 206(1):560-567. https://doi.org/10.1016/j.desal.2006.04.064 
Cho DW, Chon Y, Kim Y, Jeon BH, Schwartz FW, Lee ES, Song H (2011) Adsorption of nitrate and $\mathrm{Cr}(\mathrm{VI})$ by cationic polymermodified granular activated carbon. Chem Eng J 175:298-305. https://doi.org/10.1016/j.cej.2011.09.108

Churchman GJ, Gates WP, Theng BKG, Yuan G (2006) Clays and clay minerals for pollution control. Cap 11. Dev Clay Sci 1:625-675. https://doi.org/10.1016/S1572-4352(05)01020-2

Davis ML, Cornwell DA (2012) IIntroduction to environmental engineering. 5th edn. McGraw-Hill Education

Drzeżdżon J, Jacewicz D, Chmurzyński L (2018) The impact of environmental contamination on the generation of reactive oxygen and nitrogen species-Consequences for plants and humans. Environ Int 119:133-151. https://doi.org/10.1016/j.envint.2018.06.019

Erkan HS, Gunalp G, Engin GO (2018) Application of submerged membrane bioreactor technology for the treatment of high strength dairy wastewater. Braz J Chem Eng 35:91-100. https://doi. org/10.1590/0104-6632.20180351s20160599

Fan C, Zhang Y (2018) Adsorption isotherms, kinetics and thermodynamics of nitrate and phosphate in binary systems on a novel adsorbent derived from corn stalks. J Geochem Explor 188:95100. https://doi.org/10.1016/j.gexplo.2018.01.020

Fan AM, Willhite CC, Book SA (1987) Evaluation of the nitrate drinking water standard with reference to infant methemoglobinemia and potential reproductive toxicity. Regul Toxicol Pharmacol 7:135-148. https://doi.org/10.1016/0273-2300(87)90024-9

Foo KY, Hameed BH (2010) Insights into the modeling of adsorption isotherm systems. Chem Eng J 156:2-10. https://doi. org/10.1016/j.cej.2009.09.013

Freundlich HMF (1906) Über die ad-sorption in lösungen.In. Zeitschriftfür Physika-lische Chemie 57:385-470

Frost RL, Zhou Q, He H, Xi Y (2008) An infrared study of adsorption of para-nitrophenol on mono-, di- and tri-alkyl surfactant intercalated organoclays. Spectrochim Acta Part A Mol Biomol Spectros 69(1):239-244. https://doi.org/10.1016/j.saa.2007.02.023

Giles CH, Smith D, Huitson A (1974) A general treatment and classification of the solute adsorption isotherm. In: Theoretical. J Colloid Interface Sci 47:755-765. https://doi.org/10.1016/00219797(74)90252-5

Guan H, Bestland E, Zhu C, Zhu H, Albertsdottir D, Hutson J, Simmons CT, Ginic-Markovic M, Tao X, Ellis AV (2010) Variation in performance of surfactant loading and resulting nitrate removal among four selected natural zeolites. J Hazard Mater 183:616621. https://doi.org/10.1016/j.jhazmat.2010.07.069

He H, Huang Y, Yan M, Xie Y, Li Y (2020) Synergistic effect of electrostatic adsorption and ion exchange for efficient removal of nitrate. Colloids Surf A 584:123973. https://doi.org/10.1016/j. colsurfa.2019.123973

Hu Q, Chen N, Feng C, Hu W (2015) Nitrate adsorption from aqueous solution using granular chitosan-Fe3 + complex. Appl Surf Sci 347:1-9. https://doi.org/10.1016/j.apsusc.2015.04.049

Katal R, Baei MS, Rahmati HT, Esfandian H (2012) Kinetic, isotherm and thermodynamic study of nitrate adsorption from aqueous solution using modified rice husk. J Ind Eng Chem 18(1):295302. https://doi.org/10.1016/j.jiec.2011.11.035

Khan A, Asiri AM, Khan AAP, Khan SB (2018) Electrical conductivity and ion-exchange kinetic studies of polythiophene $\mathrm{Sn}(\mathrm{VI})$ phosphate nano composite cation-exchanger. Arab J Chem 12(7):1652-1659. https://doi.org/10.1016/j.arabjc.2014.09.004

Khan MM, Khan A, Asiri AM, Gupta V (2019a) Transport and surface charge density of univalent ion of polyvinyl chloride-based barium tungstate ion-exchange composite membrane for industrial separation of waste water. J Ind Text 49:584-596. https://doi. org/10.1177/1528083718791344

Khan A, Khan AAP, Khan I, Oves M, Khan S, Asiri AM, Azum N, Taib LA, Al Angari YM, Facchetti A (2019b) Facial synthesis of highly active polymer vanadium molybdate nanocomposite: improved thermoelectric and antimicrobial studies. J Phys Chem Solids 131:148-155. https://doi.org/10.1016/j.jpcs.2019.03.022

Kolangare IM, Isloor AM, Asiri AM, Ismail AF (2018) Improved desalination by polyamide membranes containing hydrophilic glutamine and glycine. Environ Chem Lett 17:1053-1059. https ://doi.org/10.1007/s10311-018-00825-1

Kuang P, Chen N, Feng C, Li M, Dong S, Lv L, Zhang J, Hu Z, Deng Y (2018) Construction and optimization of an iron particle-zeolite packing electrochemical-adsorption system for the simultaneous removal of nitrate and by-products. J Taiwan Inst Chem Eng 86:101-112. https://doi.org/10.1016/j.jtice.2018.02.023

Langmuir I (1918) The adsorption of gases on plane surfaces of glass, mica and platinum. J Am Chem Soc 40:1361-1403. https://doi. org/10.1021/ja02242a004

Le Moal M, Gascue-Odoux C, Menesguen A, Souchon Y, Étrillard C, Levain A, Moatar F, Pannard A, Souchu P, Lefebvre A, Pinay G (2019) Eutrophication: a new wine in an old bottle? Sci Total Environ 651:1-11. https://doi.org/10.1016/j.scitotenv.2018.09.139

Madhura L, Singh S, Kanchi S, Sabela M, Bisetty K (2018) Nanotechnology-based water quality management for wastewater treatment. Environ Chem Lett 17:65-121. https://doi.org/10.1007/s1031 1-018-0778-8

Munawer ME (2018) Human health and environmental impacts of coal combustion and post-combustion wastes. J Sustain Min 17:87-96. https://doi.org/10.1016/j.jsm.2017.12.007

Öztürk N, Bektaş TE (2004) Nitrate removal from aqueous solution by adsorption onto various materials. J Hazard Mater 112(1):155162. https://doi.org/10.1016/j.jhazmat.2004.05.001

Pan J, Gao B, Song W, Xu X, Jin B, Yue Q (2019) Column adsorption and regeneration study of magnetic biopolymer resin for perchlorate removal in presence of nitrate and phosphate. J Clean Prod 213:762-775. https://doi.org/10.1016/j.jclepro.2018.12.085

Pennington JAT (1998) Dietary exposure models for nitrates and nitrites. Food Control 9:385-395. https://doi.org/10.1016/S0956 -7135(98)00019-X

Ren Z, Xu X, Wang X, Gao B, Yue Q, Song W, Wang H (2016) FTIR, Raman, and XPS analysis during phosphate, nitrate and $\mathrm{Cr}(\mathrm{VI})$ removal by amine cross-linking biosorbent. J Colloid Interface Sci 468:313-323. https://doi.org/10.1016/j.jcis.2016.01.079

Rezakazemi M, Shirazian S (2019) Lignin-chitosan blend for methylene blue removal: adsorption modeling. J Mol Liq 274:778-791. https://doi.org/10.1016/j.molliq.2019.03.047

Roubdari A, Rezakazemi M (2018) Hormones removal from municipal wastewater using ultrasound. AMB Exp. https://doi.org/10.1186/ s13568-018-0621-4

Rungrodnimitchai S, Kotatha D (2019) New adsorbents for nitrate from modified ground tire rubber. React Funct Polym 136:9-18. https ://doi.org/10.1016/j.reactfunctpolym.2018.12.011

Ruthven DM (1984) Principles of adsorption and adsorption process. Wiley, New York, p 432

Samantya S, Kabay N, Yüksel Ü, Arda M, Yüksel M (2006) Removal of nitrate from aqueous solution by nitrate selective ion exchange resins. React Funct Polym 66:1206-1214. https://doi. org/10.1016/j.reactfunctpolym.2006.03.009

Shan R, Yan L, Yang Y, Yang K, Yu S, Yu H, Du B (2015) Highly efficient removal of three red dyes by adsorption onto $\mathrm{Mg}-\mathrm{Al}$ layered double hydroxide. J Ind Eng Chem 21:561-568. https:// doi.org/10.1016/j.jiec.2014.03.019

Sheikh M, Pazirofteh M, Dehghani M, Asghari M, Rezakazemi M, Valderrama C, Cortina JL (2020) Application of $\mathrm{ZnO}$ nanostructures in ceramic and polymeric membranes for water and wastewater technologies: a review. Chem Eng J. https://doi.org/10.1016/j. cej.2019.123475

SIECESC - Sindicato Indústria de Extração Carvão Estado Santa Catarina. http://www.siecesc.com.br/pdf/dados_estatisticos_ano_2017. pdf. Accessed 17 July 2017

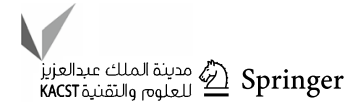


Silva MG, Muniz ARC, Hoffmann R, Lisbôa ACL (2018) Impact of greenhouse gases on surface coal mining in Brazil. J Clean Prod 193:206-216. https://doi.org/10.1016/j.jclepro.2018.05.076

Tara N, Siddiqui SI, Rathi G, Chaudhry SA, Asiri AM (2019) Nanoengineered adsorbent for the removal of dyes from water: a review 16:14-40. https://doi.org/10.2174/1573411015666190117124344

Tohdee K, Kaewsichan L (2018) Potential of BCDMACl modified bentonite in simultaneous adsorption of heavy metal Ni (II) and humic acid. J Environ Chem Eng 6:5616-5624. https://doi. org/10.1016/j.jece.2018.08.051

Tóth J (2001) Adsorption, theory, mode-ling, and analysis, 1st edn. Marcel Dekker. Inc., New York

Tyagi S, Rawtani D, Khatri N, Tharmavaram M (2018) Strategies for nitrate removal from aqueous environment using nanotechnology: a review. J Water Process Eng 21:84-95. https://doi.org/10.1016/j. jwpe.2017.12.005

USEPA - United States Environmental Protection Agency (1994) Method $4500 \mathrm{NO}_{3}{ }^{-} \mathrm{B}$. Ultraviolet spectrophotometric screening method. EPA, Washington

Viglasova E, Galambos M, Dankova Z, Krivosudsky L, Lengauer CL, Hoody-Nowotny R, Soja G, Rompel A, Matik M, Briancin J (2018) Production, characterization and adsorption studies of bamboo-based biochar/montmorillonite composite for nitrate removal. Waste Manag 79:385-394. https://doi.org/10.1016/j. wasman.2018.08.005
Xi Y, Mallavarapu M, Naidu R (2010) Preparation, characterization of surfactants modified Clay minerals and nitrate adsorption. Appl Clay Sci 48:92-96. https://doi.org/10.1016/j.clay.2009.11.047

Xie Q, Lin Y, Wu D, Kong H (2017) Performance of surfactant modified zeolite/hydrous zirconium oxide as a multi-functional adsorbent. Fuel 203:411-418. https://doi.org/10.1016/j. fuel.2017.04.141

Yaşar Ö, Uslu T, Şahinoğlu E (2018) Fine coal recovery from washery tailings in Turkey by oil agglomeration. Powder Technol 327:2942. https://doi.org/10.1016/j.powtec.2017.12.042

Zanella O, Tessaro IC, Féris LA (2015) Nitrate sorption on activated carbon modified with $\mathrm{CaCl} 2$ : equilibrium, isotherms and kinetics. Chem Ind Chem Eng Q 21:23-33. https://doi.org/10.2298/ CICEQ130830001Z

Zhao KR, Chen JY, Xu ZC, Yang DY, Yang J, Lin K (2010) Emission characteristic analysis of urban domestic pollution sources in China. Proc Environ Sci 2:761-767. https://doi.org/10.1016/j. proenv.2010.10.087

Zhou Y, Albijanic B, Tadesse B, Wang Y, Yang J, Li G, Zhu X (2019) Surface hydrophobicity of sub-bituminous and meta-bituminous coal and their flotation kinetics. Fuel 242:416-424. https://doi. org/10.1016/j.fuel.2019.01.051

Publisher's Note Springer Nature remains neutral with regard to jurisdictional claims in published maps and institutional affiliations. 